\title{
A APRENDIZAGEM BASEADA EM PROJECTOS INTERDISCIPLINARES: AVALIAÇÃO DO IMPACTO DE UMA EXPERIÊNCIA NO ENSINO DE ENGENHARIA
}

\author{
Sandra Raquel Fernandes* \\ Maria AsSUnÇão Flores** \\ Rui Manuel Lima***
}

Recebido em: 16 de outubro de 2009

Aprovado em: 15 de junho de 2010

\begin{abstract}
*Doutoramento em Ciências da Educação, na especialidade de Desenvolvimento Curricular, na Universidade do Minho, Portugal. Licenciatura em Educação, na Universidade do Minho. Actualmente, os seus interesses de investigação incluem a avaliação do impacto de metodologias de ensino e aprendizagem activas, Project-led Education (PLE) e Problem based Learning (PBL), monitorização e avaliação das aprendizagens, tutorias no Ensino Superior, ensino de Engenharia, entre outros. E-mail: sandra@dps.uminho.pt

**Professora auxiliar na Universidade do Minho. Doutoramento em Educação na Universidade de Nottingham, Reino Unido. É membro da Comissão Executiva da International Study Association on Teachers and Teaching, tendo sido eleita, em 2008, representante da Europa no International Council on Education for Teaching. E-mail: aflores@iep.uminho.pt

***Professor auxiliar no Departamento de Produção e Sistemas da Faculdade de Engenharia da Universidade do Minho, Portugal. Realizou, nesta universidade, o seu doutoramento em Engenharia de Produção Sistemas. Actualmente é o Director do Mestrado Integrado em Engenharia Gestão Industrial e tem contribuído para a implementação de diversos projectos inovadores de ensino-aprendizagem, especialmente com base em Project Led Education (PLE). E-mail: rml@dps.uminho.pt
\end{abstract}

Resumo: Neste artigo apresentamos dados de um projecto de investigação mais vasto que pretende avaliar o impacto de uma experiência de Aprendizagem Baseada em Projectos Interdisciplinares no Mestrado Integrado de Engenharia e Gestão Industrial (MIEGI). Para tal, foi utilizado o Modelo de Avaliação CIPP (Context, Input, Process, Product) de Stufflebeam (2003) como quadro de referência para a avaliação do projecto nas suas várias dimensões. O design da investigação caracterizou-se por uma metodologia eminentemente qualitativa, com recurso a alguns métodos quantitativos. Os resultados da investigação de que damos conta neste artigo baseiam-se, sobretudo, nas percepções dos estudantes sobre o processo de implementação e avaliação desta experiência. No que diz respeito ao seu impacto nos resultados e processos de aprendizagem dos alunos, ele surge associado a uma maior compreensão e aplicação dos conteúdos e ao desenvolvimento de um conjunto de competências transversais, tais como a capacidade de comunicação, de trabalho em equipa, de resolução de problemas, de gestão de conflitos e, ainda, o sentido de responsabilidade.

Palavras-chave: Ensino superior. Aprendizagem baseada em projectos. Avaliação.

\section{LEARNING BASED ON INTERDISCIPLINARY PROJECTS: EVALUATION OF THE IMPACT OF AN EXPERIMENT ON THE TEACHING OF ENGINEERING}

Abstract: This paper aims to give an overview of an ongoing and broader piece of research based on the evaluation of a Project-Led Education (PLE) experience in an Engineering and Industrial Management degree. For this, the CIPP (Context, Input, Process, Product) Evaluation Model was used as a framework for evaluating the impact of the program (Stufflebeam, 2003). Data were collected through qualitative and quantitative research methods, focusing upon students' perceptions concerning the implementation and evaluation of PLE experiences. Findings, with regard to the impact of PLE on students' learning processes and outcomes, suggest that the project provided a greater understanding and application of contents and enhanced a set of transversal skills, such as communication skills, teamwork, problem solving, project management and also sense of responsibility on students.

Key words: Higher education. Project-led education. Evaluation. 


\section{INTRODUÇÃO}

A Declaração de Bolonha trouxe para a ribalta, entre outros aspectos, a necessidade de alterar os processos de ensino / aprendizagem nas instituições de Ensino Superior dos países europeus, ao estabelecer um conjunto de directrizes do ponto de vista organizacional e pedagógico no sentido da aplicação de princípios de aprendizagem activa, da centralidade da aprendizagem dos alunos e da sua autonomia.

No âmbito de alguns estudos realizados no contexto do Ensino Superior, Tavares et al. (2004) discutem o papel do aluno, cujo envolvimento nos processos de formação e de investigação deve possibilitar o desenvolvimento das suas capacidades e a aquisição de competências básicas e específicas para uma integração bem sucedida no mundo profissional. De facto, trata-se de abandonar a visão do aluno como um "consumidor" passivo e reactivo no que diz respeito às práticas de ensino adoptadas e às decisões pedagógicas tomadas, passando a encará-lo como indivíduo consciente, responsável e competente (FLORES; VEIGA SIMÃO, 2007). Os docentes, por sua vez, tendem a reconhecer novas e maiores exigências na sua actividade pedagógica, "obrigando a um complemento entre formação inicial e contínua, no sentido de optimizar as competências pedagógica, científica e comunicacional [...]. É assim que ganha sentido a aposta na sua formação pedagógica" (FLORES; VEIGA SIMÃO, 2007, p. 3). Neste sentido, espera-se que as instituições de Ensino Superior se organizem como espaços de intervenção e de promoção do sucesso académico dos alunos, dos professores e das próprias instituições (TAVARES, 2003), de forma a responder às exigências que se vivem no contexto do Ensino Superior na actualidade.

Constata-se, assim, a crescente importância atribuída a novos modelos de ensino-aprendizagem e a uma formação centrada no estudante. O docente deixa de estar no centro do processo que passa a estruturar-se à volta da aprendizagem do estudante, privilegiando-se novas competências que não apenas a memorização e realçando a importância da realização de trabalhos de projecto, que permitem desenvolver nos alunos, além das competências técnicas da sua área de especialização, um conjunto de competências transversais, como a capacidade de comunicação, de liderança, de gestão de conflitos, de assunção de responsabilidades e de gestão do tempo, as quais constituem, igualmente, as competências mais reconhecidas e procuradas pelos empregadores. (CABRALCARDOSO; ESTEVÃO; SILVA, 2006)

A aquisição e desenvolvimento destas competências requerem ambientes de aprendizagem que estimulem o envolvimento activo dos alunos nos processos de aprendizagem, favorecendo, assim, a sua própria autonomia. Um estudo 
recente, baseado nas perspectivas dos diplomados sobre a sua formação inicial em Engenharia e a transição para o mundo profissional, mostrou que os recémdiplomados sentem bastantes dificuldades ao nível do domínio deste tipo de competências (VEIGA SIMÃO; FLORES; FLORES, 2007). Durante a sua formação inicial, as oportunidades para explorar e desenvolver estas competências têm sido, de um modo geral, escassas. (FLORES; VEIGA SIMÃO, 2007)

Neste artigo apresentamos alguns dados de um projecto de investigação mais vasto que incide na avaliação do impacto de uma experiência de Aprendizagem Baseada em Projectos Interdisciplinares no Mestrado Integrado em Engenharia e Gestão Industrial (MIEGI). Nesse sentido, foi utilizado o Modelo de Avaliação CIPP (Context, Input, Process, Product) de Stufflebeam (2003) como quadro de referência para a avaliação do projecto nas suas várias dimensões. Os resultados que apresentamos neste artigo dizem sobretudo respeito às perspectivas dos estudantes em relação a um conjunto de aspectos essenciais para a compreensão do processo de implementação da experiência e do seu impacto.

\section{APRENDIZAGEM BASEADA EM PROJECTOS INTERDISCIPLINARES}

A Aprendizagem baseada em Projectos Interdisciplinares ou Project-Led Education (PLE) surge, no contexto dos desafios decorrentes do Processo de Bolonha, como estratégia adequada à promoção de uma aprendizagem activa e centrada no trabalho autónomo do aluno. Esta metodologia, tal como a definem Powell e Weenk (2003), enfatiza o trabalho em equipa, a resolução de problemas e a articulação teoria/prática, através da realização de um projecto que culmina com a apresentação de uma solução/produto a partir de uma situação real, articulada com o futuro contexto profissional. Assim, destacamse, como principais objectivos desta metodologia, centrar a aprendizagem no aluno, fomentar o trabalho em equipa, desenvolver o espírito de iniciativa e a criatividade, desenvolver competências de comunicação, desenvolver o pensamento crítico e, por último, relacionar conteúdos interdisciplinares de forma integrada.

A metodologia PLE constitui, igualmente, uma estratégia importante para a aquisição de competências interdisciplinares, permitindo a integração dos vários conteúdos das disciplinas que participam no projecto, evitando-se, assim, a compartimentação do saber decorrente da divisão dos conteúdos em unidades curriculares, visto que os alunos aprendem através de projectos colaborativos e interdisciplinares. Este foi, na verdade, um dos principais motivos que levaram à 
adopção da metodologia PLE por parte dos docentes que leccionam o $1^{\circ}$ ano do MIEGI, visto que havia uma grande insatisfação com o ensino tradicional, que era muito compartimentado e que fornecia poucas oportunidades de interacção entre professores e alunos. (CARVALHO; LIMA, 2006)

A aplicação da metodologia PLE pressupõe trabalho em equipa por parte dos alunos para planear e realizar um projecto aberto que lhes é proposto, no qual desenvolvem as competências específicas das unidades curriculares de apoio directo ao projecto e competências transversais como as de realização de tarefas de forma cooperativa, monitorização do desenvolvimento do projecto, pesquisa e selecção de informação, negociação de conflitos e comunicação interpessoal. Outras metodologias de ensino-aprendizagem activas, como o Problem Based Learning, apresentam igualmente uma perspectiva de aprendizagem centrada no aluno e na resolução de problemas, através do trabalho em equipa, que promove a possibilidade de explorar e aperfeiçoar as competências dos alunos ao nível do relacionamento interpessoal, da capacidade de comunicação, da gestão do tempo e da iniciativa e criatividade. (GRAAFF; KOLMOS, 2003; 2007)

\subsection{O caso do curso de Engenharia e Gestão Industrial}

Ao longo dos últimos anos, os docentes do $1^{\circ}$ ano do curso de Engenharia e Gestão Industrial implementaram seis edições de processos PLE ${ }^{1}$. A equipa de coordenação do PLE é constituída por todos os docentes envolvidos na leccionação das unidades curriculares (UCs) que integram o $1^{\circ}$ semestre, pelos tutores de cada um dos grupos de alunos e, ainda, por elementos responsáveis pelo apoio pedagógico ao projecto.

Os projectos propostos aos alunos não têm uma solução única e baseiam-se em temas actuais e apelativos, constituindo um desafio quer para os alunos, quer para os docentes. A concretização do projecto requer, ainda, o desenvolvimento da maior parte das competências de aprendizagem das unidades curriculares de apoio directo ao projecto, no $1^{\circ}$ semestre do $1^{\circ}$ ano, isto é, as UCs de Introdução à Engenharia e Gestão Industrial (IEGI), Programação de Computadores 1 (PC1), Química Geral (QG) e Cálculo C (CC), tal como se ilustra na Figura 1. Apenas a unidade curricular de Introdução à Engenharia Económica (IEE) não tem participado nas recentes edições de PLE.

1 Descrições adicionais sobre a organização e o funcionamento das experiências PLE no MIEGI podem encontrar-se em Carvalho; Lima (2006), Fernandes, Flores; Lima (2008, 2007a,b); Lima, Cardoso, Pereira, Fernandes; Flores (2007); Lima, Carvalho, Flores; Van Hattum (2007). 


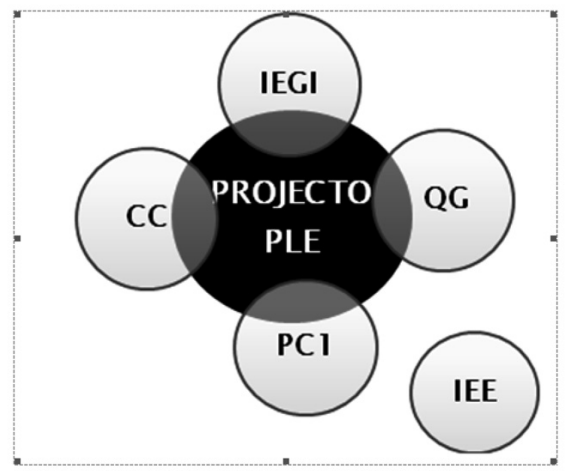

Figura 1. UCs envolvidas no PLE no $1^{\circ}$ semestre do $1^{\circ}$ ano.

Os alunos são organizados em grupos de seis/sete elementos. A cada grupo é atribuído um tutor que monitoriza o desenvolvimento do projecto e o funcionamento do grupo, servindo de elemento de ligação entre o grupo e a equipa de coordenação do projecto, transmitindo as dificuldades do grupo ao nível do projecto e do relacionamento interpessoal. (ALVES; MOREIRA; SOUSA, 2007; VEIGA SIMÃO; FLORES; FERNANDES; FIGUEIRA, 2008)

No PLE, a monitorização do processo é garantida através do estabelecimento de vários pontos de controlo (Milestones) que têm um carácter sobretudo formativo, permitindo aos alunos obter feedback dos docentes sobre o trabalho desenvolvido. Estes momentos de monitorização do projecto podem assumir diversas formas, desde apresentações formais, tutoriais alargados (reunião privada de cada grupo com toda a equipa de coordenação), entrega de relatórios, reflexões de grupo e protótipos.

A avaliação final dos alunos é efectuada com base em duas componentes: uma componente relacionada com a classificação final do aluno no projecto (40\%) e outra relacionada com a classificação resultante da avaliação contínua do aluno na UC (60\%). A classificação resultante da avaliação contínua da UC baseia-se em componentes do trabalho de projecto, mas também poderá recorrer a componentes resultantes de uma avaliação de conteúdos não abrangidos pelo projecto. A classificação individual que o aluno obtém no projecto é calculada a partir da classificação que o seu grupo obtém no projecto, sendo esta nota baseada nas seguintes componentes: relatório final preliminar (35\%), relatório final (25\%), protótipos (20\%) e apresentação e discussão final (20\%). A esta nota de projecto é aplicado um factor de correcção que resulta directamente dos processos de avaliação pelos pares, que são efectuados quatro vezes durante 
o semestre pelos respectivos colegas/alunos. A nota individual do aluno no projecto inclui ainda o resultado obtido no teste escrito sobre o projecto, com uma ponderação de $20 \%$ na classificação final do aluno no projecto.

\section{METODOLOGIA DE INVESTIGAÇÃO}

Este estudo apresenta alguns resultados de um projecto de investigação em curso no âmbito do Doutoramento em Educação, que pretende avaliar o impacto de uma experiência de PLE no curso de Engenharia e Gestão Industrial (MIEGI). O público-alvo engloba todos os participantes nas experiências de PLE que decorreram no $1^{\circ}$ ano do curso de MIEGI, desde o projecto-piloto em 2004/2005, com especial destaque para os alunos enquanto principal fonte de informação na recolha de dados. Outros intervenientes no processo, como professores, tutores e outros responsáveis pelo projecto PLE, também participam neste estudo.

De uma forma global, este projecto procura dar resposta às seguintes questões de investigação:

- Quais são as percepções dos alunos e dos professores sobre a metodologia de PLE?

- Qual tem sido o impacto desta metodologia de ensino nos resultados e processos de aprendizagem dos alunos?

- Como avaliar a qualidade de uma metodologia de ensino/aprendizagem desta natureza?

O design da investigação baseou-se, sobretudo, num paradigma de investigação qualitativo (SILVERMAN, 2001; BRYMAN, 2004), centrado em métodos e técnicas de recolha de dados pouco estruturados, visando recolher o máximo de informação possível sobre as percepções dos vários participantes envolvidos nas experiências de PLE.

Para efectuar a avaliação do projecto PLE, foi adoptado o Modelo de Avaliação CIPP (Context, Input, Process, Product) de Stufflebeam (2003) como quadro de referência para a avaliação do projecto nas suas várias dimensões. O modelo de avaliação CIPP apresenta um conjunto de pressupostos teóricos que importa destacar no sentido de compreender a adequação deste modelo ao contexto do projecto PLE. Esta proposta de avaliação centra-se, sobretudo, no contributo da avaliação para a melhoria do processo de tomada de decisão numa organização ou num determinado contexto, dado que compreende a avaliação como um processo pelo qual se delimitam, obtêm e fornecem informações úteis, que permitem julgar acerca das decisões possíveis. Trata-se, portanto, de 
um processo contínuo, que inclui essencialmente três etapas - delinear, obter e fornecer informações úteis para a tomada de decisão. A avaliação serve, assim, de guia para a tomada de decisões, proporcionando dados para a prestação de contas e promovendo a compreensão dos fenómenos envolvidos.

Este modelo de avaliação estabelece como grandes domínios de análise o contexto, os inputs (entradas) da formação, o processo formativo e os produtos obtidos (STUFFLEBEAM, 2003), a que correspondem diferentes processos de avaliação com implicações ao nível da tomada de decisão:

- A avaliação de Contexto, que diz respeito às decisões de planeamento, de identificação de necessidades, oportunidades e problemas. Tem como finalidade a tomada de decisões de planificação;

- A avaliação dos "Inputs", que engloba a análise da adequação das estratégias previstas aos objectivos do projecto, com base na qual são tomadas decisões de estruturação;

- A avaliação do Processo, que inclui as decisões de aplicação e implementação das estratégias previstas, orientando as operações do projecto;

- A avaliação do Produto, que compara os resultados obtidos com os objectivos previstos ou resultados esperados para o projecto, permitindo a tomada de decisões de revisão e melhoria.

A associação necessária entre a avaliação e a tomada de decisão, o carácter "global" e sistémico que este modelo encerra, tendo em consideração a complexidade de informações e decisões ao longo do processo e, ainda, a lógica iterativa deste modelo, que pressupõe uma interacção reversível entre os diferentes tipos de avaliação e decisão, são alguns dos motivos que justificam a eficácia e adequação deste modelo ao contexto que apresentamos neste artigo.

De forma resumida, a avaliação do contexto procura analisar a génese do PLE no MIEGI, nomeadamente através de uma análise do panorama actual do Ensino de Engenharia em Portugal e do perfil profissional requerido pelos empregadores no sentido de identificar as necessidades e prioridades no âmbito da formação dos alunos nesta área. Trata-se, essencialmente, de definir metas e objectivos a atingir com a implementação do PLE no MIEGI. Por outro lado, o contexto de ensino no Curso de Engenharia, e sobretudo as questões ligadas ao abandono e insucesso académico dos estudantes, constitui, de igual modo, um elemento importante a ter em conta nesta dimensão.

A avaliação dos inputs da formação inclui uma análise da planificação das actividades do projecto e as respectivas estratégias de acção. Trata-se de avaliar o momento da concepção e design do projecto, nomeadamente a tomada 
de decisões relativamente à definição do tema e objectivos esperados com a realização do projecto, a identificação das UC's do semestre que participam no projecto, a selecção dos tutores dos grupos, a definição dos critérios para a formação de cada grupo, a (re)definição do sistema de avaliação dos alunos, a identificação e calendarização dos momentos de monitorização do projecto e respectivos resultados esperados e, por último, a identificação dos recursos disponíveis (humanos, físicos e materiais).

A avaliação do processo formativo diz respeito à monitorização e acompanhamento do desenvolvimento do projecto, com a preocupação de recolher informação útil e oportuna para a melhoria e funcionamento da experiência. Trata-se de obter feedback dos participantes durante o processo, permitindo reajustamentos face ao plano inicialmente definido de modo a adequá-lo às necessidades dos sujeitos envolvidos na formação.

Por último, a avaliação do produto centra-se na avaliação do impacto do PLE nos resultados e processos de aprendizagem dos alunos, partindo de uma análise das percepções dos alunos, docentes e tutores que participam nestas experiências.

O Quadro 1 sintetiza os principais métodos de recolha de dados, os objectivos que pretendem alcançar, assim como os intervenientes no processo, com base nas diferentes fases da avaliação do modelo CIPP proposto por Stufflebeam (2003).

Sendo o inquérito por questionário uma técnica de recolha de dados extremamente útil para o levantamento de um número elevado de opiniões, dada a sua facilidade e rapidez em termos de modo de administração e neutralidade no que se refere à influência nas respostas dadas (BRYMAN, 2004), neste estudo, ele foi aplicado, quer no início de cada experiência PLE, para identificar as expectativas e motivações dos alunos face ao projecto, quer imediatamente após a sua conclusão, para conhecer o balanço da experiência. Para além desta avaliação "a quente", foi ainda administrado um outro questionário, ao mesmo grupo de alunos, no ano lectivo seguinte à participação no PLE, com a finalidade de conhecer e compreender quais as principais mudanças sentidas pelos alunos, ao passarem de um ensino baseado em PLE para um ensino não PLE.

Com o objectivo de completar os dados obtidos através do questionário, foram convidados vários alunos para integrar três Focus Groups. Segundo Bryman (2004), o focus group é um método que deriva quer da entrevista de grupo (onde vários participantes discutem um tópico), quer da entrevista focalizada (em que os participantes são seleccionados pelo facto de terem estado envolvidos numa situação particular). Nestas situações, importa a forma como os participantes (re)constroem as suas representações enquanto membros de um grupo e não apenas individualmente. Como refere Bryman (2004, p. 336), 


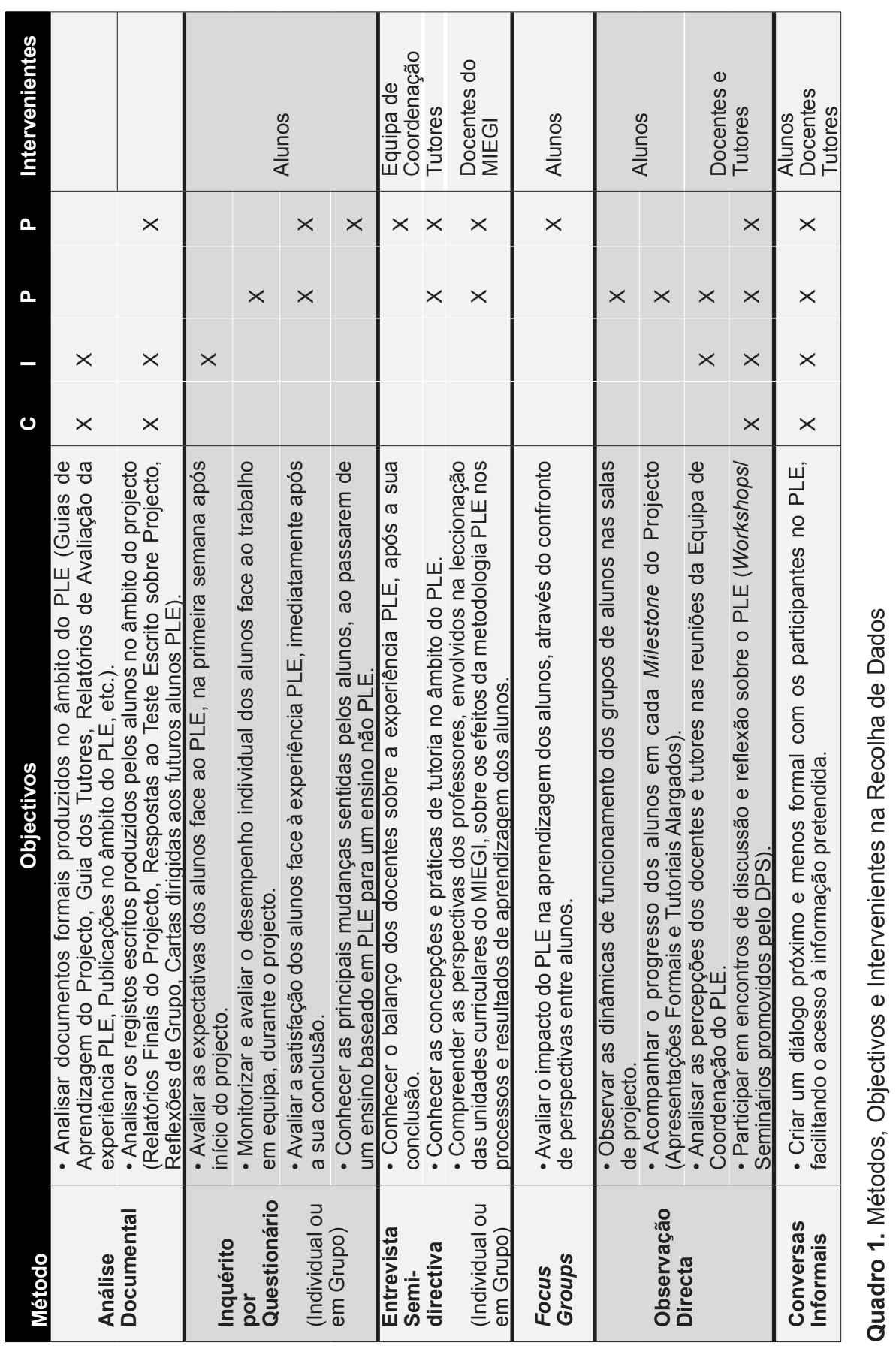


"com o focus group, o investigador está interessado em saber como as pessoas respondem umas às outras em função das suas perspectivas e constroem uma visão/entendimento a partir da interacção que ocorre no seio do grupo". De facto, pretendia-se que os alunos partilhassem a sua experiência de PLE, através da reflexão conjunta e do confronto de perspectivas e de experiências no sentido de construir uma visão ou olhar acerca do PLE em que estiveram envolvidos.

Durante o semestre, recolhemos ainda a opinião dos elementos da Equipa de Coordenação, de forma sistemática, através da participação em várias reuniões de coordenação do PLE. Para além desta informação recolhida, foi ainda realizada uma entrevista de grupo (KVALE, 1996) aos elementos da equipa de coordenação, no sentido de efectuar um balanço geral da experiência, após a sua conclusão. As características da entrevista semi-estruturada, pela sua abertura e flexibilidade na abordagem dos temas a serem tratados, e a sua natureza colectiva, permitindo o confronto de perspectivas entre os diversos participantes, facilitaram o processo de recolha de dados, no que diz respeito à auscultação da opinião de uma equipa alargada de docentes e tutores envolvidos no PLE. As entrevistas foram registadas através de gravação em áudio, sendo posteriormente transcritas e devolvidas aos participantes para verificação. O papel do investigador revelou-se fundamental no sentido de clarificar os objectivos do estudo e estabelecer um protocolo de investigação com os participantes, de modo a evitar possíveis constrangimentos provenientes do registo das informações transmitidas (BRYMAN, 2004; KVALE, 1996). Procurou-se, ao longo de todas as etapas da investigação, garantir o respeito pelos princípios da ética de investigação (SILVERMAN, 2001; KVALE, 1996), assegurando a participação consciente e voluntária sujeitos envolvidos, bem como a confidencialidade no tratamento dos dados.

Analisou-se, ainda, um conjunto de artefactos / relatos e registos escritos baseados em alguns documentos formais produzidos pelos alunos no âmbito do projecto como, por exemplo, o relatório final do projecto, as respostas dadas no teste escrito sobre o projecto, as cartas dirigidas aos futuros alunos do PLE, todos dando conta das aprendizagens adquiridas e competências desenvolvidas pelos alunos. Outros métodos complementares incluem a observação directa e as conversas informais durante o decurso das experiências de PLE.

$\mathrm{Na}$ análise dos resultados seguimos uma perspectiva sobretudo indutiva, partindo dos temas emergentes dos dados recolhidos, a partir dos quais se definiu um conjunto de dimensões e categorias, tendo por base os eixos estruturantes da metodologia PLE e os objectivos norteadores desta investigação. No âmbito deste artigo, damos conta de algumas dimensões de análise que descreveremos, com mais detalhe, na secção seguinte. 


\section{RESULTADOS}

Da análise e sistematização dos dados recolhidos, é possível destacar um conjunto de dimensões relacionadas com a organização do processo de ensino e aprendizagem no contexto da metodologia baseada no trabalho de projecto, cujas implicações ao nível do desenvolvimento curricular e do trabalho de docentes e alunos merecem particular destaque. De acordo com os objectivos e âmbito do presente artigo, serão apresentadas as perspectivas dos estudantes sobre um conjunto de aspectos essenciais para a compreensão do processo de implementação da experiência e do seu impacto. A abordagem seguida para a análise dos dados baseou-se sobretudo numa perspectiva indutiva (MILES; HUBERMAN, 1994), tentando identificar os temas emergentes dos discursos dos estudantes, a partir das dimensões consideradas estruturantes na metodologia PLE. Neste artigo, abordaremos, em particular, as seguintes dimensões: a articulação curricular, o desenvolvimento de competências transversais, o papel do professor e do aluno e, por fim, o processo de avaliação e os resultados académicos.

\section{a) Articulação Curricular}

Os alunos reconhecem o contributo do projecto para uma melhor compreensão e articulação dos conteúdos das diversas unidades curriculares do semestre. Nas respostas dadas a um teste escrito sobre o projecto, os alunos destacam a interdependência dos saberes disciplinares como um factor potenciador de um maior estudo e interesse pelas UCs, que se reflectiu na transferência e aplicação dos conceitos abordados nas aulas para o contexto específico do projecto:

O facto de as UCs estarem integradas no PLE facilitou de certo modo o estudo das mesmas, já que era realmente necessário saber certos conteúdos para realizar o trabalho, além de que isso fomentou o interesse por essas mesmas disciplinas, pois ao mesmo tempo que dávamos a matéria víamos aplicações práticas da mesma. Para concretizarmos o projecto temos de ter uma compreensão geral dos conteúdos abordados nas diferentes UCs de forma a conseguirmos aplicá-los e utilizá-los de modo coerente ao longo do projecto.

Fiquei surpreendido como, por vezes, para atingir um objectivo era necessário relacionar vários conteúdos das diferentes UCs.

Respostas ao Teste sobre o Projecto 
No caso das unidades curriculares na área das Ciências, cujo insucesso académico no $1^{\circ}$ ano do curso tem sido um aspecto recorrente, reconhece-se uma melhor compreensão e aplicação das matérias por parte dos alunos, quando a disciplina está inserida no PLE (LIMA, CARVALHO, FLORES; VAN HATTUM, 2007). A transposição dos conteúdos (abstractos) para situações reais e concretas facilita o processo de aprendizagem dos alunos. Os alunos apontam uma das unidades curriculares como um claro exemplo disso.

A aplicação de CC [Cálculo C] foi muito interessante, pois fazer integrais parece uma coisa que não tem interesse nenhum e o cenário mudou de figura quando se tornaram necessários para o cálculo das dimensões da bateria.

Resposta ao Teste sobre o Projecto

E havia coisas que nós estávamos nas aulas e a pensar para que é que isto nos ia servir para a vida futura e aprendemos algumas coisas que até são úteis. Por exemplo, a Cálculo... aquilo das integrais e assim... afinal vimos que aquilo até era útil para alguma coisa...

Focus Group A

Este é, aliás, um dos aspectos que vai ao encontro dos objectivos subjacentes à aprendizagem baseada em projectos na lógica da promoção da interdisciplinaridade dos saberes, uma das mais valias da integração das disciplinas através do projecto (POWELL; WEENK, 2003). Heitmann (1996) sublinha, a par disso, a crescente importância atribuída à necessidade de uma melhor compreensão daquilo que se aprende, como um dos factores-chave associados às experiências baseadas em projectos.

Nas recentes edições de PLE, sobretudo após a implementação do teste escrito sobre o projecto, foi possível evidenciar, com maior profundidade, o contributo do PLE para a promoção da articulação curricular das disciplinas. De facto, neste teste escrito, elaborado pelos docentes responsáveis pela leccionação das UCs que participam no PLE e que inclui um conjunto de questões específicas de cada projecto desenvolvido pelos diferentes grupos, foi inserida ainda uma questão global direccionada para o tema da interdisciplinaridade das unidades curriculares, na qual os alunos teriam de demonstrar, com base em exemplos concretos, de que forma é que os conteúdos das disciplinas se relacionavam entre si. As respostas dos alunos a esta questão global têm sido bastante elucidativas, na medida em que evidenciam uma clara articulação 
entre as matérias leccionadas e a sua aplicação no projecto, estabelecendo uma relação coerente entre os objectivos do projecto e as competências requeridas pelas diferentes unidades curriculares.

Salienta-se, assim, a importância de estabelecer momentos de reflexão e de auto-avaliação dos alunos, durante a realização do projecto, que permitam aferir sobre as aprendizagens adquiridas e desenvolvidas e sobre o alcance dos objectivos propostos pelo projecto. De facto, a criação de dispositivos de monitorização e avaliação integrados no processo (FERNANDES; FLORES; LIMA, 2007b), com a função essencialmente reguladora e formativa, pode potenciar momentos de reflexão e de metacognição sobre o contributo do projecto para a aprendizagem dos alunos, o que nem sempre tem acontecido. O teste sobre o projecto, ao tratar-se de um mecanismo de avaliação sumativo, fomentou a necessidade de uma reflexão mais ponderada e consciente dos reais ganhos adquiridos com o projecto. Reconhece-se, assim, o predomínio de uma concepção de aprendizagem e de avaliação centradas, ainda, em mecanismos de controlo formais, que servem a finalidade primordial de comprovar e classificar os conhecimentos adquiridos. Este aspecto poderá ser reforçado por algumas percepções dos alunos, recolhidas numa fase posterior à participação no PLE, que mostram a preferência de alguns alunos pelo ensino não PLE, realçando precisamente a vantagem de este não requerer uma articulação e aplicação dos conhecimentos e o facto de a avaliação da unidade curricular ser exclusivamente baseada nos respectivos conteúdos leccionados.

O método do $2^{\circ}$ ano [de MIEGI] é mais benéfico para nós, pois dão a matéria mais direccionada para os testes e não para o tema do projecto.

Com o PLE, além das dúvidas normais das matérias, ainda tínhamos que superar as dificuldades do projecto (dúvidas de como e onde aplicar as matérias, etc.). Este ano, penso que as dificuldades são em menor número e mais fáceis de se superarem, pois são apenas relacionadas com matéria dada nas aulas.

Questionário de Avaliação Final

Estas percepções dos alunos remetem-nos para uma visão de aprendizagem caracterizada pela compartimentação dos saberes por áreas disciplinares, sem preocupação com a sua articulação e relevância para a formação do aluno, na linha de uma concepção de formação académica mais tradicional relacionada mais com a aprovação às disciplinas do que com a própria compreensão dos 
saberes e com a valorização de outras competências fundamentais para o exercício da profissão, como é o caso do trabalho em equipa, da capacidade de comunicação, das competências de relacionamento interpessoal, de gestão de projectos, etc.

Por oposição a esta visão mais fragmentada da aprendizagem, outros alunos salientam a necessidade de conferir sentido às aprendizagens, através de exemplos concretos ligados à sua área de intervenção enquanto profissionais de Engenharia.

Normalmente numa universidade aprende-se conteúdos e mais conteúdos e depois reflecte-se: E se um dia chegar a Engenheiro como vou usar o que aprendi?, pois bem o PLE auxilia o estudante a usar o que aprende nas UCs em casos reais.

É bastante interessante do ponto de vista de não estudarmos apenas para os testes, mas também a integração das UCs na vida real.

Esta integração contribuiu para não sermos apenas espectadores, mas sermos activos e em vez de ficarmos apenas pela teoria conseguimos partir para a prática.

Respostas ao Teste sobre o Projecto

Este ano [Não PLE] é mais dificil chegar até essa utilidade. [...] Mas depois aquelas disciplinas mais teóricas, fazer a ponte entre a realidade e aquilo que estamos a dar, é muito mais dificil.

Focus Group A

\section{b) Desenvolvimento de Competências Transversais}

A componente prática que o projecto engloba constitui uma fonte de motivação para os alunos, tornando visível a aplicação prática dos conceitos, o que confere ao projecto um carácter mais real e articulado com o contexto profissional futuro, estimulando os alunos a trabalharem com mais entusiasmo e empenho.

Veiga Simão e Flores (2007), partindo da análise de alguns estudos realizados, sublinham a necessidade de, no contexto do Ensino Superior, se promover um conjunto de competências, no aluno universitário, tais como aprender a pensar, a cooperar, a comunicar, a gerir emoções, a ser crítico e a auto-motivarse. No contexto do PLE, os dados resultantes da monitorização e avaliação do processo permitiram dar conta das potencialidades do trabalho de projecto 
na promoção do desenvolvimento desse conjunto alargado de competências. Também os alunos que participaram neste estudo sublinham a importância e desenvolvimento destas competências.

Contudo, e porque se trata de um projecto ao longo de um semestre, surgem algumas dificuldades identificadas pelos estudantes, as quais são associadas sobretudo ao processo de desenvolvimento do projecto, nomeadamente à gestão do projecto e ao relacionamento interpessoal. Ao nível da gestão do projecto, os grandes desafios concentram-se na coordenação de horários, no cumprimento de prazos e na organização e planeamento das tarefas do projecto. Ao nível do relacionamento interpessoal, as principais dificuldades passam por aprender a gerir situações de conflito possivelmente causadas pela divergência de opiniões e ideias, pelo confronto de posturas e de atitudes, pela divergência dos objectivos individuais e pela falta de comunicação dentro do grupo.

Estas dificuldades, que naturalmente acontecem durante a concretização do projecto, exigem estratégias para as ultrapassar. Entender estas dificuldades como desafios e saber como superá-los constitui um momento importante de aprendizagem que tem sido valorizado pelos alunos.

Aprendemos também a trabalhar em equipa, a resolver conflitos internos no grupo, para que estes não interferissem com o desenvolvimento do projecto, adquirimos experiência a apresentar, o à vontade nas apresentações, aprendemos a redigir correctamente relatórios, tomamos conhecimento de áreas para as quais nem sequer pensávamos, ou seja, aprendemos a trabalhar num projecto em equipa, que no futuro vai-nos ser muito útil.

Carta dirigida aos futuros alunos do PLE

A lidar com as diferenças dos outros... Acho que isso foi muito interessante para nós. Saber que a outra pessoa tem uma opinião diferente da nossa mas tentarmos sentar todos numa mesa e trabalhar.

Acho que os grupos todos tiveram os seus problemas. Uma coisa boa foi toda gente tentou resolvê-los de uma maneira ou de outra. Também eram problemas que não valiam a pena... e isso era um dos objectivos do PLE - era ultrapassar os problemas.

Focus Group A 
O trabalho colaborativo é, na verdade, uma característica intrínseca às abordagens baseadas em projecto ou na resolução de problemas (HELLE; TYNJÄLÄ; OLKINUORA, 2006). No caso do PLE no MIEGI, o trabalho realizado pelos alunos desenvolve-se num ambiente predominantemente cooperativo, dada a partilha efectiva das tarefas no âmbito do projecto pelos elementos do grupo e a sua responsabilização na construção de um resultado partilhado cujo resultado é da responsabilidade de todos. Estas são, igualmente, as competências mais procuradas e valorizadas pelos empregadores de diplomados (MESQUITA; LIMA; PEREIRA, 2008). Torna-se cada vez mais premente a necessidade de uma formação inicial voltada para o desenvolvimento de competências que vão para além dos conhecimentos teóricos e da sua aplicação e transferência directa para os contextos profissionais. Os empregadores reclamam, cada vez mais, por profissionais competentes, responsáveis e capazes de lidar com situações de incerteza e mudança, o que obriga a uma selecção cada vez mais rigorosa e criteriosa dos diplomados a contratar. (HEYWOOD, 2005; MARKES, 2006)

Esta constatação começa a ser também motivo de preocupação por parte dos alunos ainda durante a sua formação académica. De facto, foi possível identificar esta consciencialização da necessidade de estar preparado para enfrentar as condições exigidas pelo mercado de trabalho, em várias das respostas recolhidas por parte dos alunos, que aparecem, ao mesmo tempo, como uma das mais valias da abordagem PLE.

Com o PLE há uma aplicação mais prática dos conhecimentos adquiridos nas diferentes UCs, deste modo ficamos mais preparados para a realidade do mercado de trabalho.

Questionário de Avaliação Final

Nas aulas aprendiamos os fundamentos teóricos e no projecto PLE conseguiamos efectuar diversas aplicações práticas desses fundamentos teóricos. Isto foi uma novidade para os alunos, visto até aqui nada disto acontecia, [...] mas eu penso que esta aplicação da teoria em termos práticos contribuiu imenso para a nossa aprendizagem, isto porque assim poderíamos exemplificar onde é que a teoria poderia ser aplicada em exemplos reais.

Resposta ao Teste sobre o Projecto

De facto, constata-se que as recentes mudanças verificadas ao nível dos programas curriculares dos cursos do Ensino Superior procuram dar resposta 
não só a necessidades de natureza pedagógica, que se traduzem na adopção de práticas de ensino e de aprendizagem com enfoque na compreensão e aplicação dos saberes, como também razões que provêm das novas exigências do mercado profissional e indústria, que requerem profissionais detentores de um conjunto alargado de competências que lhes possibilitem uma actuação eficaz e eficiente em ambiente profissional. (HELLE; TYNJÄLÄ; OLKINUORA, 2006)

\section{c) Processo de Avaliação e Resultados Académicos}

O processo de avaliação dos alunos, no âmbito do PLE, tem sido objecto de reflexão e de discussão, tendo sido alvo de contínuas alterações e melhorias, dada a sua natureza complexa e abrangente. Por esse motivo, a temática da avaliação tem surgido no discurso dos alunos como um dos aspectos que mais influencia a (in)satisfação e (des)motivação dos alunos face aos processos de aprendizagem e resultados obtidos no âmbito da metodologia PLE. (FERNANDES; LIMA; FLORES, 2009)

Dados provenientes de inquéritos por questionário e de focus groups, realizados após a conclusão das experiências de PLE junto dos alunos, demonstram as vantagens e constrangimentos que este modelo de avaliação pressupõe. Por um lado, o carácter contínuo e formativo do processo de avaliação pressupõe um envolvimento activo por parte dos alunos que, durante a realização do projecto, realizam diversas actividades no âmbito do cumprimento dos milestones ou pontos de controlo previstos na calendarização do projecto. Para alguns alunos, este constitui um aspecto positivo dada a dificuldade que normalmente têm em conseguirem manter um estudo e acompanhamento das unidades curriculares de forma contínua, o que é fortemente potenciado pela necessidade de aplicar os conteúdos no projecto e pela realização do trabalho em equipa. Deste modo, a aplicação dos conteúdos em situações reais torna a aprendizagem mais significativa e relevante para os alunos, ao mesmo tempo que permite manter o seu empenho e dedicação nas tarefas relacionadas com o projecto.

Com esta metodologia reconheço que o empenho é contínuo e o acompanhamento das matérias leccionadas está em constante emprego. Desta forma, o contacto com a realidade empresarial está desde cedo presente.

Questionário de Avaliação Final

Eu antes de vir para a universidade... estudar era mesmo em cima da hora. E aqui [PLE], eu tinha aquela obrigação. E 
depois não podia ficar por ali porque sabia que tinha que fazer mais senão não iria conseguir perceber as coisas e depois isso ia-se reflectir depois nas notas. [...] Porque se só existisse um relatório, nós iríamos deixar tudo para o fim e os resultados não iriam ser tão bons. Enquanto que, por haver pontos de controlo, nós todas as semanas estávamos aí.

Focus Group A

Contudo, existe também alguns desafios e/ou dificuldades que derivam da natureza interdisciplinar do projecto, dado que exige que todos os elementos estruturantes do currículo, isto é, os objectivos de aprendizagem, as actividades de ensino-aprendizagem, os conteúdos e os processos de avaliação, se articulem ao longo do semestre e sejam equilibrados em termos de volume de trabalho e de resultados a alcançar. Caso contrário, poderá criar situações que levam os alunos a encarar o projecto e as unidades curriculares como algo isolado, tendo que fazer escolhas em termos de prioridades e de gestão do tempo. Este aspecto foi, aliás, um dos aspectos evidenciados pelos alunos durante um dos focus groups, que dá conta da dificuldade em gerir o tempo e sobretudo as solicitações e as tarefas relacionadas com o projecto a par das exigências das diferentes UCs:

[No PLE] Nós tínhamos que gerir a parte da disciplina que era para o projecto e a que não era nos testes. Nós tínhamos um teste e na semana a seguir tínhamos que entregar o relatório. Muitas vezes havia a escolha entre estudar para o teste ou trabalho para o relatório. Edaí. Acho que muitas vezes abdicamos de estudar para o teste para trabalharmos para o PLE.

O PLE rouba muito tempo. Não conseguimos ter tempo para fazer as coisas bem. Conseguimos fazê-las, isso conseguimos. Mas não nos deixa chegar onde nós sabemos que conseguimos chegar.

Focus Group C

As implicações do trabalho individual e colectivo, no âmbito da metodologia de avaliação do PLE, constituem outro aspecto amplamente debatido pelos alunos. Verifica-se que a maior parte dos alunos, apesar de considerar o trabalho em equipa interessante e motivador, prefere que a avaliação esteja apenas dependente de si próprios, pois argumentam que os resultados seriam 
mais justos. Para os alunos, o modelo de avaliação ideal é aquele que apenas depende do esforço individual do aluno para alcançar bons resultados mas que, ao mesmo tempo, não traz consequências ao nível colectivo quando os resultados são menos bons. Por este motivo, alguns alunos revelam maior preferência pelo ensino não PLE visto que, neste contexto, cada aluno é responsável pelos resultados obtidos, estando o sucesso na UC apenas dependente de si próprio e não de um grupo. A sua percepção da avaliação é de que, no ensino não PLE, as notas são superiores porque os alunos têm mais tempo para estudar e isso reflecte-se directamente nas notas.

Penso que os resultados obtidos agora [Não PLE] são melhores pois temos mais tempo para estudar e isso reflecte-se positivamente nas notas. Além disso, o PLE era desvantajoso porque trabalhávamos imenso mas em termos de notas não se reflectia na mesma proporção.

Este semestre [Não PLE] sinto-me mais envolvido nas UCS porque o tempo de estudo é completamente aplicado no estudo das matérias dadas. Assim o esforço aplicado na UC tem directa relação com a nota. Sinto-me mais motivado pois sei que, desta forma, tudo o que trabalho na disciplina é para melhorar a nota.

Questionário de Avaliação Final

Com a realização dos Focus Groups, foi possível discutir com os alunos as questões relativas à metodologia de avaliação do PLE de uma forma mais aprofundada. Isto permitiu reflectir sobre a multiplicidade de significados que a avaliação encerra para os alunos, alguns deles paradoxais. Destacamos, aqui, alguns comentários que contrastam com a visão redutora da avaliação mencionada anteriormente, sendo reconhecido pelos alunos que o processo de avaliação no PLE promove a avaliação de outro tipo de competências, que se processam em ambientes de aprendizagem cooperativos, desenvolvendo o sentido de responsabilidade e a capacidade de relacionamento e comunicação interpessoal.

E outra coisa boa é que nós não nos preocupávamos só com os nossos resultados. A partir do momento em que nós trabalhávamos em grupo eu acho que foi isso que fez com que eu me tornasse uma pessoa mais responsável ou ainda mais respon- 
sável. Mais responsável porque eu não me considerava uma pessoa irresponsável. Mas foi o facto de eu não poder falhar porque se não o meu grupo também ia falhar. E eu acho que foi isso que nos ajudou muito.

Eu acho o PLE avaliava competências diferentes. Eu acho que nós agora [não PLE] só estamos a ser avaliados pelos conhecimentos que temos ou que demonstramos ter. E no PLE não. Acho que avaliam a nossa capacidade de trabalho em grupo, as nossas apresentações, capacidade de passar ideias, de comunicar.

O nosso objectivo era também ganhar mas [...] era tentar ser melhor do que os melhores. E uns com os outros tentarmos sempre ser melhores. Agora se tentarmos ser todos iguais, não vai haver progressão. Temos que tentar ser melhores do que os outros. E tentar que no caminho todos melhorem.

Focus Group A

\section{d) Papel do Professor e do Aluno}

Ao longo dos últimos anos, a experiência adquirida pelos docentes e tutores que participam no PLE tem sido um factor importante para o sucesso desta experiência. $\mathrm{O}$ facto de já conhecerem o seu processo de organização e, sobretudo, os seus resultados, facilita a preparação e (re)adaptação dos programas curriculares e das práticas pedagógicas (aulas de acompanhamento do projecto ou tutorias) de modo a ir ao encontro dos objectivos preconizados pelo projecto. No caso de uma das disciplinas, dada a rotatividade dos docentes envolvidos na sua leccionação, tem sido mais difícil conseguir esta integração efectiva devido à ausência, a priori, de uma visão clara sobre o papel da UC no projecto. No entanto, após a conclusão do projecto, vários têm sido os docentes que reconhecem um conjunto de melhorias a introduzir na sua UC de modo a contribuir mais significativamente para os objectivos do projecto. De facto, verificamos que o processo de aprendizagem, no contexto do trabalho baseado em projectos, é efectivamente bidireccional, ou seja, não são apenas os alunos que aprendem e desenvolvem novas competências - aos docentes também é lançado o repto de se adaptarem às novas exigências pedagógicas e curriculares que encaram o perfil do professor do ensino superior como o de 
um sujeito crítico e reflexivo, aberto à mudança, pensando o ensino centrado na aprendizagem e onde o trabalho docente se desenrola em ambientes cooperativos e colaborativos. (VEIGA SIMÃO; FLORES, 2007)

Assim, verificámos que o sucesso destas abordagens de projecto requer, efectivamente, um esforço acrescido por parte dos docentes para adequarem os conteúdos programáticos da respectiva unidade curricular aos objectivos específicos de cada projecto. Isto pressupõe, ainda, um envolvimento activo dos docentes das unidades curriculares na fase de concepção e definição do tema e dos objectivos do projecto, bem como alguma flexibilidade e capacidade de adaptação de modo a que seja possível dar resposta às necessidades sentidas pelos alunos durante a sua realização. Alguns testemunhos recolhidos pelos alunos, numa fase posterior à participação no PLE, permitem confirmar estes desafios que se colocam aos docentes, implicando um papel mais crítico e reflexivo, quando integrados numa metodologia de PLE.

Se calhar como nós tínhamos um trabalho prático, os professores tinham o trabalho de deixar a parte teórica e investir mais na parte prática. E agora [Não-PLE], como nós agora não temos projecto, estamos a ser massacrados com mais teoria, como na disciplina X... temos um trabalho, mas é só mais aquela teoria pura..

Isso [PLE] obrigava os professores a aprender também com aquilo que nós estávamos a fazer e agora [não-PLE] eles trabalham aquela teoria que têm nos livros e estão a passar para nós... Sebentas de 1999... Praticamente nós não passamos nada para eles! [...] E eu acho que as dúvidas que nós vamos pondo ao longo do projecto também podem levar a que eles direccionem as aulas noutro sentido. Porque percebem que nós estamos a ter outro tipo de necessidades. Eu acho que isso é bastante importante...

Focus Group A

A relação que se estabelece entre professor e aluno, no contexto do PLE, também tem sido sublinhada pelos alunos como um factor positivo que contribui para melhorar o processo de aprendizagem. De facto, os alunos referem que o relacionamento entre professor/aluno no PLE é mais próximo e efectivo do que no ensino não PLE, traduzindo-se, por exemplo, no esclarecimento de dúvidas sobre a matéria e/ou objectivos do projecto. 
[a relação proflaluno] Foi das melhores com o PLE uma vez que a aproximação permitiu um melhor esclarecimento de algumas matérias.

Questionário de Avaliação Final

Por exemplo, nas Orientações Tutórias de Cálculo, ele tinha a preocupação de saber como é que estava a andar o projecto $e$ até ia ao quadro fazer exercícios relacionados com o projecto. E depois não tínhamos que chegar a sala de reuniões e estar a fazer tudo por nós.. Tínhamos já aquela direcção que nos foi dada.

Focus Group A

No ano passado [PLE] éramos capazes de chegar a uma aula e perguntar qualquer coisa para o projecto a um professor, tipo "professor o que é que acha?" ou "professor, não percebo bem isto".. acho que aconteceu a todos, a Química e a Cálculo, acho que todos nós tivemos esses periodos. E este ano [Não $P L E]$, não estou a ver como é que podemos fazer isso.

Focus Group B

Como já se disse, o trabalho colaborativo é também um dos pressupostos da metodologia PLE, quer no trabalho desenvolvido pelos alunos, quer na coordenação e articulação entre a equipa de docentes (e tutores) envolvidos. No caso do PLE, constata-se que a equipa de coordenação trabalha, efectivamente, como uma equipa de projecto, com reuniões periódicas e papéis rotativos em cada reunião desempenhados por todos os elementos. A interacção sistemática entre docentes e tutores permite uma intervenção atempada no caso de serem diagnosticados problemas no funcionamento dos grupos ou no desempenho individual de alguns alunos. Cumpre, ainda, o papel formativo da avaliação (ALLAL, 1986; HADJI, 2001) que se pretende neste tipo de metodologias de ensino-aprendizagem baseadas em projecto, em que o feedback e o apoio aos alunos na regulação da sua própria aprendizagem são preocupações que se procuram ter em conta. Nesta concepção de avaliação de natureza construtivista (GUBA; LINCOLN, 1989), que encara a avaliação como um processo negociado e interactivo, recolhendo informação dos resultados por referência aos processos, Fernandes (2005, p. 62) confirma que: 
A avaliação formativa deve ser a modalidade privilegiada, com a função de melhorar e regular as aprendizagens. [...] O feedback, nas suas mais variadas formas, frequências e distribuições, é um processo indispensável para que a avaliação se integre no processo de ensino-aprendizagem.

No âmbito do PLE, foi possível identificar diversas situações que se reportam ao modo como o feedback e o apoio fornecidos aos alunos constituiu uma mais-valia para a aprendizagem dos alunos.

Nós no relatório não recebiamos só a nota, para além disso tínhamos o feedback. Tínhamos a oportunidade de corrigir. Porque nós entregávamos o primeiro relatório e depois tínhamos o segundo e mesmo no último entregaram-nos a correcção e nós pudemos fazer uma coisa melhor. Acho que se aprende muito com os erros.

Focus Group A

\section{CONCLUSÕES E IMPLICAÇÕES}

A experiência PLE no MIEGI representa um contributo significativo no alcance dos objectivos do processo de Bolonha, nomeadamente no que se refere aos processos de ensino e aprendizagem centrados na aprendizagem do estudante e ainda às mudanças desejáveis ao nível do trabalho dos docentes. Os resultados deste estudo corroboram outras investigações realizadas no contexto do Ensino Superior, as quais procuram reflectir sobre as situações e as condições para uma aprendizagem mais activa e significativa, destacando, por exemplo, a importância de criar ambientes de aprendizagem e de trabalho cooperativo, envolvendo equipas de professores e equipas de alunos, com responsabilidade partilhada e sentido de autonomia para gerir a sua própria aprendizagem e desenvolvimento pessoal e profissional. (TAVARES et al., 2004; VEIGA SIMÃO; FLORES, 2007)

O estudo empírico realizado no contexto do MIEGI permitiu analisar e compreender as percepções dos estudantes relativamente à metodologia PLE e aos seus efeitos nos processos e nos resultados de aprendizagem dos alunos. A este nível - aquilo que os alunos aprendem e a forma como aprendem - verificou-se que a natureza complexa e dinâmica do projecto permitiu, a par de uma melhor compreensão dos conteúdos abordados nas diversas UCs e da sua utilidade e 
relevância, conseguidos graças à dimensão prática e contextualizada do projecto, desenvolver nos alunos um conjunto de competências que se revelaram cruciais para o sucesso do trabalho em equipa e do projecto realizado, nomeadamente, trabalho em equipa, resolução de problemas, gestão do tempo, capacidade de relacionamento interpessoal, capacidade de comunicação, oral e escrita, entre outras competências.

Em geral, são de destacar como aspectos mais positivos ligados à metodologia PLE a interdisciplinaridade e articulação dos conteúdos, o desenvolvimento de competências transversais, a avaliação formativa e o feedback, etc.

No que diz respeito à metodologia de avaliação dos alunos, foi possível dar conta das potencialidades, mas também das fragilidades ou dos desafios que se colocam numa avaliação de natureza essencialmente formativa, com preocupação pela monitorização dos processos e pela avaliação das competências disciplinares e transdisciplinares. Nesse sentido, os alunos reclamam por um sistema de avaliação e classificação que tenha em consideração não só a qualidade das aprendizagens realizadas, mas também o esforço e empenho dedicados ao projecto durante a sua realização.

O papel do docente e do aluno implicam também uma outra postura que assenta na centralidade da aprendizagem do estudante, na autonomia, na flexibilidade e na articulação de conteúdos e de estratégicas pedagógicas, na avaliação formativa, etc. Alguns destes aspectos são potenciados pelo PLE, como ficou visível através da voz dos estudantes de que demos, sumariamente, conta neste artigo. Contudo, existe um conjunto de aspectos que carecem de maior reflexão e aprofundamento, nomeadamente a questão da avaliação, formativa e sumativa, o papel do tutor (aquele que apoia e monitoriza e aquele que avalia) e as condições para o trabalho colaborativo entre docentes no ensino superior. A este propósito, levantam-se ainda várias interrogações. Estarão os docentes realmente preparados para uma participação mais activa por parte dos estudantes? Quais as competências necessárias para os papéis que se esperam dos docentes e dos estudantes? Quais as condições necessárias para o desenvolvimento da autonomia dos estudantes? Estarão os docentes dispostos a rever modos de trabalho pedagógico? Estarão os docentes preparados para desenvolver tutorias? Estarão os docentes predispostos para reverem modos de abordagem (extensão e profundidade) dos conteúdos na sua área disciplinar numa perspectiva de desenvolvimento global? Estarão os docentes preparados para trabalhar em equipa? Estas são questões que merecem mais debate e reflexão e serão objecto de análise a partir dos dados recolhidos junto dos docentes e dos tutores. 


\section{REFERÊNCIAS}

ALLAL, Linda. Estratégias de avaliação formativa: concepções psicopedagógicas e modalidades de aplicação. In: ALLAL, Linda; CARDINET, Jean; PERRENOUD Philippe (Dirs.). Avaliação formativa num ensino diferenciado. Coimbra: Livraria Almedina, 1986. p.175 - 209.

ALVES, Anabela; MOREIRA, Francisco; SOUSA, Rui. O papel dos tutores na aprendizagem baseada em projectos: Três anos de experiência na Escola de Engenharia da Universidade do Minho. In: BARCA, A. (Eds.). Libro de Actas do Congresso Internacional Galego-Portugués de PsicoPedagoxía. Revista Galego-Portuguesa de Psicoloxía e Educación, Coruña: Universidade da Coruña, p. 1759-1770, 2007. Número extraordinário da Revista Galego-Portuguesa de Psicoloxía e Educación.

BOGDAN, Robert C.; BIKLEN, Sari K. Investigação qualitativa em educação. Uma introdução à teoria e aos métodos. Porto: Porto Editora, 1994.

BRYMAN, Alan. Social research methods. Oxford : Oxford University Press, 2004.

CABRAL-CARDOSO, Carlos; ESTEVÃO, Carlos; SILVA, Paulo. As competências transversais dos diplomados do ensino superior: perspectiva dos empregadores e dos diplomados. Guimarães: TecMinho, 2006.

CARVALHO, Dinis; LIMA, Rui M. Organização de um processo de aprendizagem baseado em projectos interdisciplinares em engenharia. In: MARTIN, Z. et al. (Orgs.). CONGRESSO BRASILEIRO DE ENSINO DE ENGENHARIA COBENGE'2006, 34., Passo Fundo. Passo Fundo, Rio Grande do Sul: Universidade de Passo Fundo, 2006. p. 1475-1488.

FERNANDES, Domingos. Avaliação das aprendizagens: desafios às teorias, práticas e políticas. Lisboa: Texto Editores, 2005.

FERNANDES, Sandra; FLORES, Maria A.; LIMA, Rui M. Avaliação de uma experiência de ensino-aprendizagem baseada em projectos interdisciplinares. In:. BRITO, C. R.; CIAMPI, M. M. (Eds.). Proceedings of ICECE 2007 International Conference on Engineering and Computer Education. Monguaguá, Brasil: COPEC - and IEEE, 2007a. p. 422-426. 
FERNANDES, Sandra; FLORES, Maria A.; LIMA, Rui M. Project-led education in engineering: monitoring and assessing the learning process. In: SZENTIRMAI, L.; GYULA, T., SZARKA, (Eds.). Proceedings of SEFI and IGIP Joint Annual Conference. Miskolc: University of Miskolc, 2007b. 1 CD-ROM.

FERNANDES, Sandra; FLORES, Maria A.; LIMA, Rui M. Assessing the Impact of project-led education: a case study at the University of Minho. In: KOLMOS, Anette; DU, Xiangyun, (Eds.). Research Symposium on Problem-Based Learning in Engineering Education. Aalborg: UNESCO Chair Problem-Based Learning, 2008.

FERNANDES, Sandra; FLORES, Maria Assunção; LIMA, Rui Manuel. Engineering students' perceptions about assessment in project-led education. In: DOMINGUEZ; Urbano, (Ed.). Proceedings of the International Symposium on Innovation and Assessment of Engineering Curricula. Valladolid, Spain: [s.n.], 2009. p. 161-172.

FLORES, Maria A.; VEIGA SIMÃO, Ana M. Competências desenvolvidas no contexto do Ensino Superior: a perspectiva dos diplomados. In: JORNADAS DE REDES DE INVESTIGACIÓN EN DOCENCIA UNIVERSITARIA, 5., 2007, Alicante. Actas... Alicante, Espanha: Universidade de Alicante, 2007.

GRAAFF, Erik de; KOLMOS, Anette. Characteristics of problem-based learning. International Journal of Engineering Education, United States of America, n. 17, v. 5, p. 657-652, 2003.

GRAAFF, Erik de; KOLMOS, Anette. Management of change implementation of problem-based and project-based learning in engineering. Rotterdam: Sense Publishers, 2007.

GUBA, Egon G.; LINCOLN, Yvonna S. Fourth Generation evaluation. London: Sage, 1989.

HADJI, Charles. A avaliação, regras do jogo. Das intenções aos instrumentos. Porto: Porto Editora. 1994.

HEITMANN, Günter. Project-oriented study and project-organized curricula: a brief review of intentions and solutions. European Journal of Engineering Education, United Kingdom, v. 2, n. 21, p. 121-132, 1996. 
HELLE, Laura; TYNJÄLÄ, Päivi; OLKINUORA, Erkki. Project-based learning in post-secondary education - theory, practice and rubber slings shots. Higher Education, Netherlands, v. 51, n. 2, 287-314, 2006.

HEYWOOD, John. Engineering education. Research and development in curriculum and instruction. New Jersey: IEEE Press, 2005.

KVALE, Steinar. Interviews: an introduction to qualitative research interviewing. Thousand Oaks: Sage Publications, 1996.

LIMA, Rui M., CARVALHO, José D., FLORES, Maria A.; VAN HATTUMJANSSEN, Natascha. A case study on project led education in engineering: students' and teachers' perceptions. European Journal of Engineering Education, United Kingdom, v. 32, n. 3, p. 337 - 347, 2007.

LIMA, Rui M.; CARDOSO, Elisabete; PEREIRA, Guilherme; FERNANDES, Sandra; FLORES, Maria A. A aprendizagem baseada em projectos interdisciplinares num curso de engenharia: uma leitura dos resultados académicos. In: BARCA, A. et al. (Eds.). Libro de Actas do Congresso Internacional Galego-Portugués de PsicoPedagoxía. A Coruña: Universidade da Coruña, 2007. p. 1269-1280. Número extraordinário da Revista Galego-Portuguesa de Psicoloxía e Educación.

MARKES, Imren. A review of literature on employability skill needs in engineering. European Journal of Engineering Education, United Kingdom, v. 31, n. 6, p. 637-650, 2006.

MESQUITA, Diana, LIMA, Rui M.; PEREIRA, Guilherme. Engenharia e gestão industrial em Portugal: uma visão da procura profissional. CONGRESSO LUSO-MOÇAMBICANO DE ENGENHARIA (CLME'2008), 5., 2008, Moçambique. Moçambique: Maputo, 2008.

MILES, Matthew B.; HUBERMAN, Michael. Qualitative data analysis. An expanded source book. Thousand Oaks: Sage, 1994.

POWELL, Peter C.; WEENK, Wim. Project-led engineering education. Utrecht: Lemma Publishers, 2003.

SILVERMAN, David. Interpreting qualitative data. Methods for analysing talk, text and interaction. London: Sage Publications, 2001. 
STUFFLEBEAM, Daniel. The CIPP model for evaluation. Disponível em: $<$ http://www.wmich.edu/ evalctr/pubs/CIPP-ModelOregon10-03.pdf $>$. Acesso em: 12 jan. 2009.

TAVARES, José. Formação e inovação no ensino superior. Porto: Porto Editora, 2003.

TAVARES, José et al. Docência e aprendizagem no ensino superior. Investigar em Educação. Revista da Sociedade Portuguesa de Ciências de Educação, Porto, n. 3, p. 15-55, 2004.

VEIGA SIMÃO, Ana M., FLORES, Maria A., FERNANDES, Sandra; FIGUEIRA, Célia. Tutoria no ensino superior. Concepções e práticas. Sísifo. Revista de Ciências da Educação, Lisboa, n. 7, p. 75-88, 2008. Disponível em: $<$ http://sisifo.fpce.ul.pt $>$. Acesso em: 12 jan. 2009.

VEIGA SIMÃO, Ana M.; FLORES, Maria A. Oportunidades e desafios no ensino superior: resultados de alguns estudos realizados em Portugal. In: JORNADAS DE REDES DE INVESTIGACIÓN EN DOCENCIA UNIVERSITARIA, 5. 2008, Alicante. Actas... Alicante, Espanha: Universidade de Alicante, 2008.

VEIGA SIMÃO, Ana M., FLORES, Maria A.; FLORES, Paulo. Graduates' views on their initial training: challenges for higher education. In: INTERNATIONAL CONFERENCE, INTERNATIONAL STUDY ASSOCIATION ON TEACHER THINKING - ISATT "TOTEMS AND TABOOS: RISK AND RELEVANCE IN RESEARCH ON TEACHERS AND TEACHING, 13., 2007, Ontario. Proceedings... Ontario, Canada: Brock University, 2007. (peer reviewed). 